\title{
Particulates in the atmosphere of Makkah and Mina valley during the Ramadan and Hajj seasons of 2004 and 2005
}

\author{
A. R. Seroji \\ The Custodian of the Tow Holy Mosques Institute of Hajj Research, \\ Umm Al-Qura University, Saudi Arabia
}

\begin{abstract}
This work has been devoted to study TSP, $\mathrm{PM}_{10}$ and $\mathrm{PM}_{2.5}$ in the atmosphere of Makkah and the Mina valley during the Ramadan and Hajj periods, 1424 and $1425 \mathrm{H}$. On the occasion of Hajj, about 2.5 million persons gather in Makkah and move to Mina valley $\left(4 \mathrm{~km}^{2}\right), 7 \mathrm{~km}$ outside east of Makkah. Pilgrims spend 3 nights in the valley. Congested traffic and the high rates of emissions in such a valley of small area coupled with severe weather conditions, make the area ideal for the accumulation of air pollutants. The present investigation shows that the diurnal cycle of $\mathrm{PM}_{10}$ in air coincides with the pattern of traffic movements. Particulate matters $\left(\mathrm{PM}_{10}\right)$ daily concentrations in the atmosphere of the Mina valley ranged between $191-262 \mu \mathrm{g} / \mathrm{m}^{3}$ during the presence of the pilgrims in Mina compared to the European standard of $50 \mu \mathrm{g} / \mathrm{m}^{3}$. These concentrations represent $34 \%-40 \%$ of TSP. These high $\mathrm{PM}_{10}$ concentrations are due to the massive transportation movements at Mina valley. Moreover, TSP concentrations reached $665 \mu \mathrm{g} / \mathrm{m}^{3}$ in the Makkah atmosphere during the last ten days of Ramadan compared to the Saudi standard of $340 \mu \mathrm{g} / \mathrm{m}^{3}$. Chemical analysis of $\mathrm{PM}_{10}$ indicated high levels of sulphates, ammonium, nitrates and chlorides. For example, the concentrations of nitrates and sulphates of $\mathrm{PM}_{10}$ were about $4.9 \%$ and $6.1 \%$ respectively, compared to $2.1 \%$ of nitrates and $2.7 \%$ of sulphates in TSP. Health dangers that might be encountered by pilgrims due to these pollutants were estimated. It is recommended to set a well planned air quality management program to protect the air of Makkah.
\end{abstract}

Keywords: Makkah, Mina, particulates, $P M_{10}, P M_{2.5}$, pilgrims, transportation. 


\section{Introduction}

Makkah, Saudi Arabia is the holy city for Muslims. Mina valley lies just outside Makkah, $7 \mathrm{~km}$ to the east of the city centre and the holy mosque (Al-Masjid AlHaram). Towards the Muslim pilgrimage period every year, Muslims start to gather in Makkah at the beginning of Zulhijah (the last month of the Muslims calendar year). Pilgrims (more than 2.5 millon) move on the $8^{\text {th }}$ of Zulhijah to Mina Valley. They stay in the valley for one night before they proceed to Arafat (about $12 \mathrm{~km}$ to the south) on the morning of the $9^{\text {th }}$ of Zulhijah, "Day of AlWakffah". On the early morning of $10^{\text {th }}$ of Zulhijah, all pilgrims return to Mina on their way back to Makkah. This time they spend 3 days "Tashreek days" and sleep in tents at Mina which has an area of $4 \mathrm{~km}^{2}$, and each pilgrim has less than $2 \mathrm{~m}^{2}$ to live on. Sources of air pollution are mainly fuel combustion with reference to auto exhaust and the movements on the bottom of the valley and the surrounding mountains. Means of transportation are mainly automobiles. The central area of Makkah is characterized by a very dense population, high buildings, narrow streets, and congested traffic flow. Congestion and high rates of pollutant emissions in such valleys of small areas coupled with predominant weather condition of high temperature, lack of rainfall, prevailing one wind direction, low wind speeds and the potentiality of thermal inversions make the area an ideal situation for the accumulation of air pollutants. The problem is of concern when scavenging mechanisms fail to dilute pollutants, pilgrims may face an acute health problem (Nasralla [1]).

This study has discussed the concentration levels of particulate in the atmosphere of Makkah and Mina valley during the Ramadan and Hajj seasons in 2004 and 2005. The assessments of health risks for pilgrims are also presented.

\section{Methodology}

The air pollution monitoring program was conducted in Makkah and Mina valley to monitor air pollutants $\left(\mathrm{CO}, \mathrm{SO}_{2}, \mathrm{NO}_{\mathrm{x}}, \mathrm{O}_{3}\right.$ and particulates $)$ and weather elements during pilgrimage periods of 2004 and 2005 (1424 and 1425H). Particulate matters were also measured in Makkah during the month of Ramadan (October 2004). Total suspended particulates, $\mathrm{PM}_{10}$ and $\mathrm{PM}_{2.5}$ were sampled using high volume samplers, $\mathrm{PM}_{10}$ sampler and $\mathrm{PM}_{2.5}$ sampler (Staplex Co.) respectively during pilgrimage period in Mina valley. Measurements were carried out at two levels. The first level is $4 \mathrm{~m}$ above the ground surface and the second level is $1.6 \mathrm{~m}$ at the entrance of one of the pilgrims' tents. Sampling period started during both years of the study on $5^{\text {th }}$ to $15^{\text {th }}$ of Zulhijah in 1424 and $1425 \mathrm{H}\left(27^{\text {th }}\right.$ Jan. $-6^{\text {th }}$ Feb. 2004, and $14^{\text {th }}-25^{\text {th }}$ Jan. 2005). Total suspended particulates were sampled in three locations at Makkah city. These sites are (a) the central area adjacent to the holy mosque, (b) city centre about $1 \mathrm{~km}$ distance from the holy mosque and (c) Alazizia residential district at a distance of $6 \mathrm{~km}$ west of the central area of Makkah and about $2 \mathrm{~km}$ east of Mina valley. PM10 was also continuously monitored at the central area of Makkah adjacent to the holy mosque using ambient particulate monitor (beta ray absorption). TSP, 
$\mathrm{PM}_{10}$ and $\mathrm{PM}_{2.5}$ were sampled on quartz filters during pilgrimage period in Mina Valley. TSP in Makkah locations were sampled using glass fiber filters. Ions in half of each sample were extracted using deionised water and analysed for chlorides (titrimetry), ammonium and nitrates (colouremetry) and sulphates (turbidimetry) according to the methods described by Nasralla [2]. Particulate samplers were periodically calibrated using air flow calibration kit. Quality assurance/Quality control program for chemical analysis include the extraction of clean filter using deionised water. This extraction was used as a blank and solutions of known concentrations of analysed ions were used for standardization of the analysis procedures.

\section{Results and discussions}

\subsection{Particulate concentrations during Ramadan period}

Fig. 1 shows the recorded TSP concentrations in the atmospheres of the three monitored locations in Makkah during the month of Ramadan 1424H (Oct/ Nov 2004). About 2 million people visited Makkah to pray in the holy mosque during nights of Ramadan. They spend 1-4 nights in the city. The number of the visitors increased gradually reaching its peak during the last 10 days, that is the days between the $20^{\text {th }}$ and $27^{\text {th }}$ of Ramadan. The movements of the visitors and their vehicles in the central area of Makkah have been reflected on the concentrations of particulates in the city air. This is very clear from the differences between the TSP concentrations recorded in the atmospheres of the three sites of measurements and the significant increase of TSP during the last 10 days as compared to those found at the beginning of the month (fig. 1). Here, it should be noted that TSP reached a concentration of $665 \mu \mathrm{g} / \mathrm{m}^{3}$ during the $20^{\text {th }}$ of Ramadan including the night of the $21^{\text {st }}$. This concentration is much higher than the Saudi Air Quality Standard of $340 \mu \mathrm{g} / \mathrm{m}^{3}$. Fig. 1 also indicated that TSP in the atmosphere of the residential area, $6 \mathrm{~km}$ out of the city centre, was only $25 \%$ higher than the daily limit of $120 \mu \mathrm{g} / \mathrm{m}^{3}$, previously recommended by WHO [3].

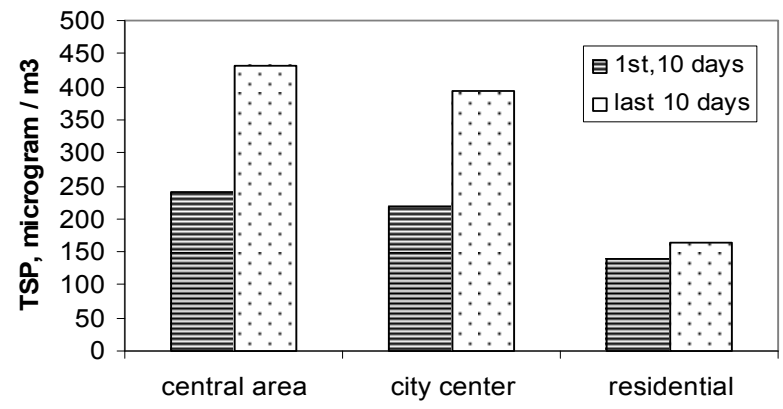

Figure 1: TSP in Makkah atmosphere during Ramadan 1424H (Oct/Nov 2004. 
Daily average concentrations of TSP in the air of the central area of Makkah reached levels as much as twice of that previously recommended limit of WHO [3]. Moreover, TSP concentrations in the central area during the peak time of the days $20^{\text {th }}-27^{\text {th }}$ of Ramadan reached three times more than those found in the air of the residential area and reaching about 5 times of that previously recommended by WHO [3]. Here, it should be noted that WHO removed their guide line for particulate matters from recent publication WHO [4] and stated that there is no safe limit can be recommended for particulates above $20 \mu \mathrm{g} / \mathrm{m}^{3}$. These high levels of TSP extended to cover the surrounding air of Makkah city centre (fig. 1). Moreover, the daily average concentrations of $\mathrm{PM}_{10}$, during the last 10 days of the month, reached levels of more than $250 \mu \mathrm{g} / \mathrm{m}^{3}$ with a maximum value of $800 \mu \mathrm{g} / \mathrm{m}^{3}$ at midnight of $21^{\text {st }}$ of the month. In the absence of Saudi standard for $\mathrm{PM}_{10}$, these concentrations may be compared to the European standard of $50 \mu \mathrm{g} / \mathrm{m}^{3}$.

\subsection{Particulate concentrations during Hajj period}

The results of the particulates monitoring program during the pilgrimage period (Hajj) show clearly the impact of transportation and the movements of pilgrims on the variations in concentrations of particulate in the atmospheres of the Makkah and Mina valley. Results indicated three different trends of daily variations in TSP concentrations in the air of the three sites of measurements as shown in fig. 2. It may be seen that the lowest concentrations at the three locations were recorded on the $9^{\text {th }}$ of Zulhijah in $1424 \mathrm{H}\left(31^{\text {st }}\right.$ Jan., 2004). On that day all pilgrims moved to Arafat valley, $19 \mathrm{~km}$ to the SE of Makkah and $12 \mathrm{~km}$ of Mina valley. Here, it should be noted that the high levels of TSP reflected the movements of the pilgrims with their vehicles in Makkah, Mina and back to stay in Makkah. In other words, the highest levels of particulates were recorded in the places they live at or move to. Fig. 2 also shows that TSP concentrations

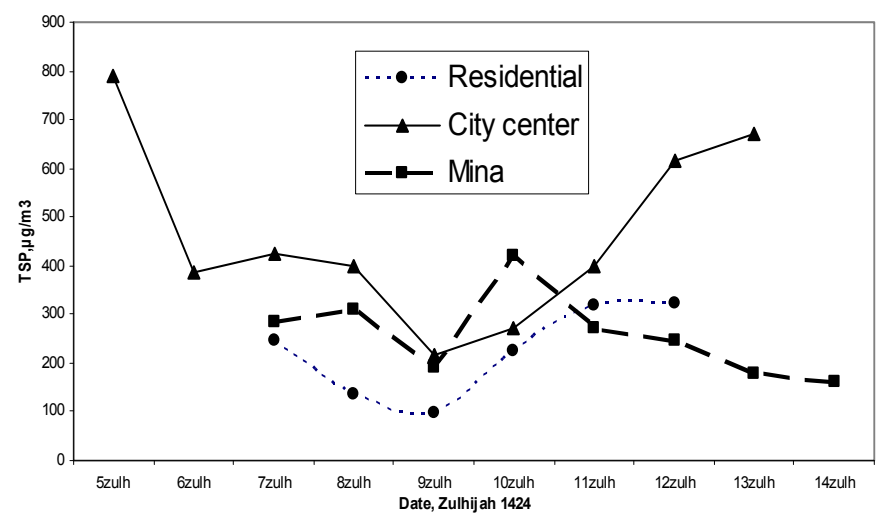

Figure 2: TSP in Makkah and Mina atmospheres during pilgrimage session, Zulhijah 1424H (Jan / Feb 2004). 
increased to levels of $>200 \%$ during their residence in Mina and $>300 \%$ during their stay in Makkah as compared to concentrations recorded on the $9^{\text {th }}$ of Zulhijah when they moved to Arafat valley. Here, it should be noted that the early morning movements of vehicles in Makkah and Mina on the $9^{\text {th }}$ of Zulhijah resulted in TSP concentrations twice that recorded in the residential area of Alazizia on the same day. This furthermore confirms the contribution of transportation in polluting the air of Makkah and Mina with particulate matters. Results of the present work show that $\mathrm{PM}_{10}$ concentrations in Mina valley followed the same pattern with regard to TSP daily variation during the period of the pilgrims' occupancy of the valley. The recorded PM10 concentration in the atmosphere of the valley on the $9^{\text {th }}$ of Zulhijah in $1424 \mathrm{H}\left(31^{\text {st }}\right.$ Jan. 2004) was less than $50 \mu \mathrm{g} / \mathrm{m}^{3}$ and peaked to $137 \mu \mathrm{g} / \mathrm{m}^{3}$ on the return of the pilgrims back to Mina on the $10^{\text {th }}$ of Zulhijah ( $\left(1^{\text {st }}\right.$ Feb. 2004).

Furthermore, fig. 3 shows the concentrations of TSP, $\mathrm{PM}_{10}$ and PM2.5 in the Mina valley during the pilgrimage period of $1425 \mathrm{H}$ (January 2005). These figures clearly confirm the influence of the vehicles and movements of pilgrims on the concentrations of particulates in the air of the valley. $\mathrm{PM}_{10}$ daily concentrations in the atmosphere of Mina valley ranged between $191-262 \mu \mathrm{g} / \mathrm{m}^{3}$ during the pilgrims' occupancy of Mina. These concentrations represent 34\%$40 \%$ of TSP. This percentage of $\mathrm{PM}_{10}$ is similar to that found in several urban areas such as Cairo (Nasralla [5] and Nasralla et al. [6]), Athens (Chaloulakou et al. [7]), China (Ying et al. [8]) and several other cities of the world (WHO [4, 9]). Furthermore, high levels of $\mathrm{PM}_{2.5}$ have been recorded in the atmosphere of the valley representing $34 \%-42 \%$ of the recorded $\mathrm{PM}_{10}$ concentrations. One of the interesting findings of this work is that the levels of $\mathrm{PM}_{2.5}$ and $\mathrm{PM}_{10}$ at $4.5 \mathrm{~m}$ above the ground surface did not vary much than those recorded at $1.6 \mathrm{~m}$ at the entrance of one of the pilgrim's tents. Knowing that pilgrims usually sleep in tents as well as outside and around streets, it can be concluded that pilgrims are exposed to high levels of these air pollutants with deleterious effects on their health. Here, it should be noted that WHO [10] stated that there is no safe limit for the exposure to $\mathrm{PM}_{10}$ levels above $20 \mu \mathrm{g} / \mathrm{m}^{3}$.

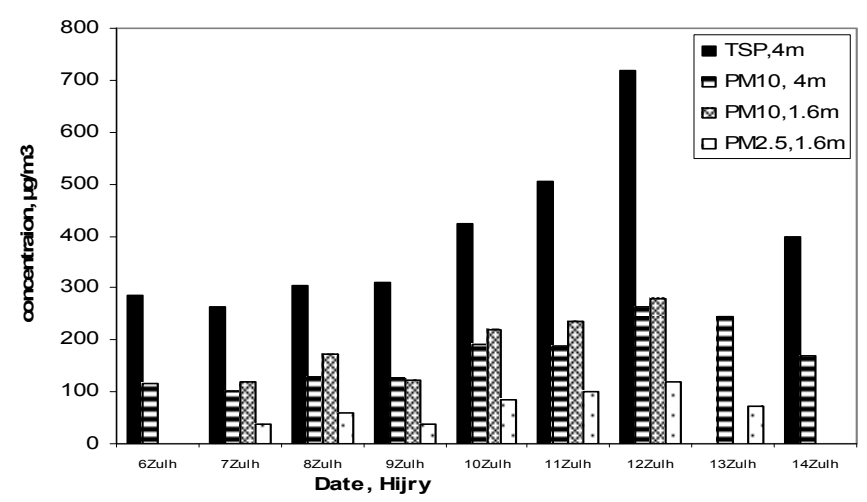

Figure 3: TSP, $\mathrm{PM}_{10}$ and $\mathrm{PM}_{25}$ in Mina Valley during pilgrimage $1425 \mathrm{H}$, Jan 2005. 
Similarly, pilgrims were exposed to high levels of $\mathrm{PM}_{10}$ during their residence in Makkah close to the central area (fig. 4). These daily concentrations of $\mathrm{PM}_{10}$ recorded in the atmosphere of Makkah may be compared to the European United Community (EUC) air quality standard of $50 \mu \mathrm{g} / \mathrm{m}^{3}$. Moreover, it may be seen that the pattern of $\mathrm{PM}_{10}$ variation in Makkah air during the different occasions of pilgrimage was very similar during both years (2004 and 2005) of the study (see fig. 4). This confirms the reflection of man's activities with reference to transportation on the concentrations of $\mathrm{PM}_{10}$ in the air of Makkah central area.

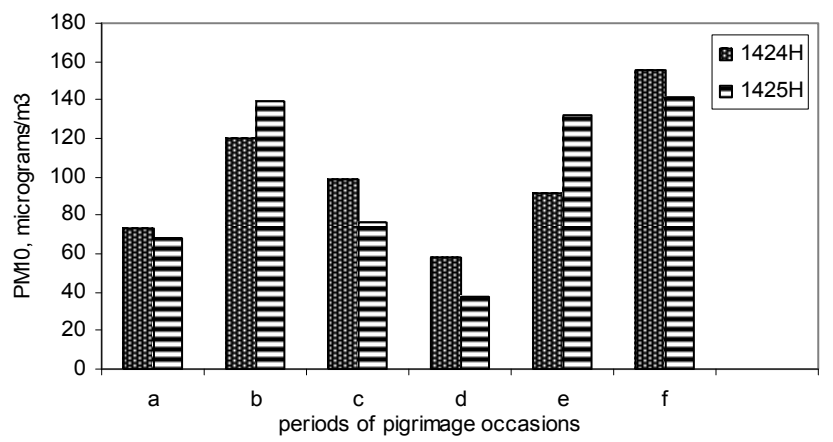

Legend: a, before pilgrims arrival to Makkah, $24^{\text {th }}-29^{\text {th }}$ of Zulkedda

$\mathrm{b}$, residence in Makkah before pilgrimage, $1^{\text {st }}-6^{\text {th }}$ of Zulhijah

c, leaving to Mina and Arafat, $7^{\text {th }}$ and $8^{\text {th }}$ of Zulhijah

d, Arafat day, $9^{\text {th }}$ of Zulhijah

$\mathrm{e}$, residence in Mina and moving between Mina and Makkah, $10^{\text {th }}-12^{\text {th }}$ of Zulhijah

$\mathrm{f}$, back to stay in Makkah, $14^{\text {th }}-20^{\text {th }}$ of Zulhijah

Figure 4: $\quad \mathrm{PM}_{10}$ in Makkah central area during various pilgrimage occasions.

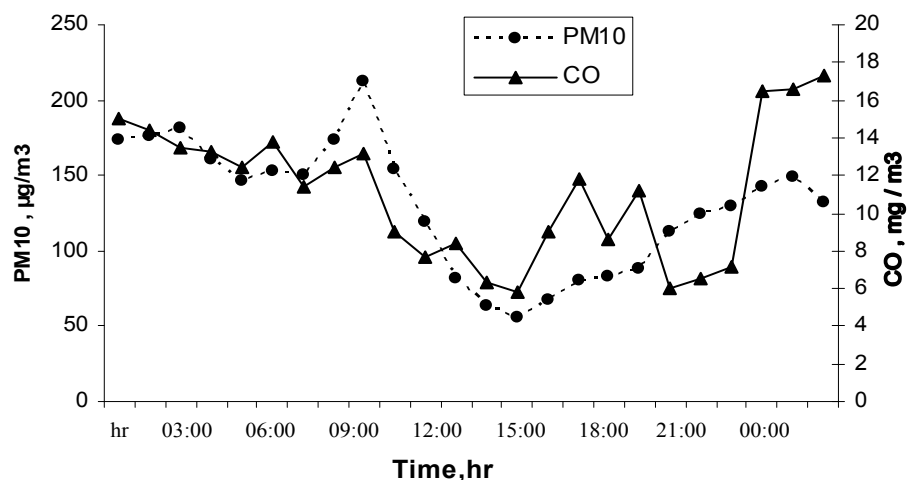

Figure 5: Diumal variation of $\mathrm{CO}$ and $\mathrm{PM}_{10}$ in Makka central area, Zulhijah 1425H, 14 Jan 2005. 
This conclusion is furthermore confirmed by the diurnal variation of $\mathrm{PM}_{10}$ and $\mathrm{CO}$ in Makkah air (figs. 5 and 6). These figures indicated, to a great extent, similar diurnal cycles for both air pollutants. Furthermore, the increase of $\mathrm{PM}_{10}$ concentrations in Makkah air during night time is very similar to that recorded in Mina valley. This cannot only be explained by the movements of vehicles 24 hours daily during pilgrimage, but is possibly due to the nocturnal formation of a stable and stagnant atmosphere and the long periods of calm or light winds during night times.

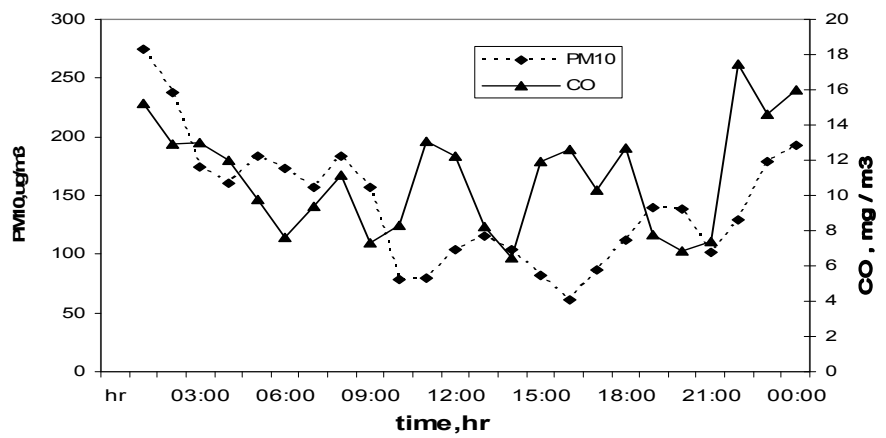

Figure 6: Diurnal variation of $\mathrm{CO}$ and $\mathrm{PM}_{10}$ in the atmosphere of Makka central area, 14 Zulh, 24 Jan 2005.

\subsection{Estimated health risks in Mina during Hajj season}

Analysis of particulate samples collected from the Mina atmosphere during "Tashreek days" indicated that $\mathrm{PM}_{10}$ contains high levels of nitrates $\left(\mathrm{NO}_{3}{ }^{-}\right)$, sulphates $\left(\mathrm{SO}_{4}^{--}\right)$, ammonium $\left(\mathrm{NH}_{4}{ }^{+}\right)$and chloride $\left(\mathrm{Cl}^{-}\right)$compared to those encountered in TSP (table 1). The high levels of nitrates, sulphates, ammonium and chloride recorded in PM10 samples are in accordance with previous findings in several European urban areas (Clarke [11] and WHO [9]).

Table 1: $\quad$ Average concentrations of $\mathrm{PM}_{10}$ and TSP anions in Mina.

\begin{tabular}{|c|c|c|c|c|}
\hline Ion & $\begin{array}{c}\mathrm{TSP}, \\
\%\end{array}$ & $\begin{array}{c}\mathrm{PM}_{10}, \\
\%\end{array}$ & $\begin{array}{c}\mathrm{TSP}, \\
\mu \mathrm{g} / \mathrm{m}^{3}\end{array}$ & $\begin{array}{c}\mathrm{PM}_{10}, \\
\mu \mathrm{g} / \mathrm{m}^{3}\end{array}$ \\
\hline $\mathrm{NO}_{3}{ }^{-}$ & 2.1 & 4.9 & 7.8 & 6.3 \\
$\mathrm{SO}_{4}^{-}$ & 2.7 & 6.1 & 10 & 7.9 \\
$\mathrm{NH}_{4}^{+}$ & 1.8 & 3.8 & 6.7 & 4.9 \\
$\mathrm{Cl}^{-}$ & 1.4 & 1.9 & 5.2 & 2.5 \\
\hline
\end{tabular}

A trial was made to assess the health risks for pilgrims during their residence in Makkah and Mina due to the exposure to $\mathrm{PM}_{10}$. 
Calculations were conducted according to eqns. (1), (2), (3), (4) given by WHO [10], (see table 2).

$\%$ increase in daily mortality $=(0.07 \pm 0.012) \times \mathrm{PM}_{10} \ldots \ldots$

$\%$ change in hospitals admission $=(0.084 \pm 0.033) \times \mathrm{PM}_{10} \ldots$

$\%$ change in cough $=(0.455 \pm 0.228) \times \mathrm{PM}_{10}$

$\%$ change in symptom exacerbation $=(0.345 \pm 0.162) \times \mathrm{PM}_{10}$.

Table 2: Estimated risks for pilgrims health during residence in Mina, pilgrimage $1425 \mathrm{H}$ (2005).

\begin{tabular}{|c|c|c|c|c|}
\hline & $\begin{array}{c}\% \\
\text { increase } \\
\text { in } \\
\text { mortality }\end{array}$ & $\begin{array}{c}\% \text { change } \\
\text { in } \\
\text { hospitals } \\
\text { admission }\end{array}$ & $\begin{array}{c}\% \\
\text { change } \\
\text { in } \\
\text { cough }\end{array}$ & $\begin{array}{c}\% \text { change in } \\
\text { symptom } \\
\text { exacerbation }\end{array}$ \\
\hline Mina & $13->16$ & $16->23$ & $\begin{array}{c}86- \\
>123\end{array}$ & $65->101$ \\
\hline Makkah & $8-14$ & $10-14$ & $51-77$ & $39-59$ \\
\hline
\end{tabular}

The high temperature and relative humidity, existence of high concentrations of other air pollutants and the required heavy physical activities and high particulate concentrations are likely to cause adverse health effects during "Tashreek days" in Mina and during their residence in Makkah central district. It is important to keep in mind that more than 350,000 pilgrims were aged over 50 years and more than 75,000 over 65 years of age CDSI [12] and are thus more susceptible to the adverse effects of air pollutants on health. It is recommended to conduct thorough investigations and source apportionment studies to evaluate the exact contribution of the different types of vehicles to the problem of $\mathrm{PM}_{10}$ in Makkah and Mina. In fact, well planned air quality management and an alternative transportation system are urgently recommended for Makkah and holy places.

\section{Conclusion}

TSP, $\mathrm{PM}_{10}$ and $\mathrm{PM}_{2.5}$ in the atmosphere of the Makkah and Mina valley were measured during Ramadan and Hajj periods. $\mathrm{PM}_{10}$ daily concentrations in Mina valley ranged between $191-262 \mu \mathrm{g} / \mathrm{m}^{3}$. Analysis of $\mathrm{PM}_{10}$ indicated high levels of sulphates, ammonium, nitrates and chlorides as compared to TSP. The concentrations of TSP and $\mathrm{PM}_{2.5}$ in different periods of time were also estimated.

\section{Acknowledgement}

The authors acknowledge the support of the Custodian of the Tow Holy Mosques Institute of Hajj Research, Umm Al-Qura University, Makkah for financial support and providing facilities. 


\section{References}

[1] Nasralla, M.M. Carbon monoxide and photochemical oxidants in Mina valley during pilgrimage, Arab Gulf Journal of Scientific Research, 4 (1), pp. 193-201, 1986.

[2] Nasralla, M.M., Air pollution in subtropical Saudi urban area, Environment International, 9, pp. 255-264, 1983.

[3] WHO, Air Quality Guidelines, $1^{\text {st }}$ Edition, World Health Organization, Regional Office for Europe, Copenhagen, Denmark, 1987.

[4] WHO, Air Quality Guidelines, Global Update 2005, Particulate matters, ozone, nitrogen dioxide and sulfur dioxide, World Health Organization $(W H O)$, Regional Office for Europe, Copenhagen, Denmark, 2006.

[5] Nasralla, M.M. Carcinogenic, toxic and microbial contaminants in Cairo air, Final Report, Academy of Science and Technology, Cairo, Egypt, 1997.

[6] Nasralla, M.M , Ali, E. A, Hassan, W. H. and Shahat F., Size distribution and chemistry of particulate matters in Cairo atmosphere, $3^{\text {rd }}$ International Conference on the Environment, NRC, Cairo, 2006.

[7] Chaloulakou A., Kassomenos P., Grivas G., Spyrellis N., Particulate matter and black smoke concentration levels in central Athens, Greece. Environment International, 31, pp. 651-659, 2005.

[8] Ying Wang, Guoshun Zhuang, Xingying Zhang, Kan Huang, Chang Xu, Aohan Tang, Jiamin Chen, Zhisheng An, The ion chemistry seasonal cycle and sources of aerosol in Shanghai. Atmospheric Environment, 33, pp. 843853, 2006.

[9] WHO, Air Quality Guidelines, $2^{\text {nd }}$ Edition, World Health Organization (WHO), Regional Office for Europe, Copenhagen, Denmark, 2000.

[10] WHO, Guidelines for Air Quality, World Health Organization (WHO), Geneva, 2000a.

[11] Clarke, A.G., Particle size and chemical composition of urban aerosols, The Science of the Total Environment, 23(5), pp. 15-24, 1999.

[12] CDSI, (Central Department of Statistics \& Information), Results of statistical data of pilgrims for Hajj season in 1425, Ministry of Economic \& Planning, 2005. 